\title{
Trabalho e cooperação: apresentação do dossiê
}

Trabajo y cooperación: presentación del dossier

Travail et coopération: présentation du dossier

Work and cooperation: presentation of the dossier

Cirlene de Souza Christo, Jussara Brito, Letícia Pessoa Masson, Marcelo Figueiredo e Paulo César Zambroni-de-Souza

\section{OpenEdition}

\section{Journals}

\section{Edição electrónica}

URL: http://journals.openedition.org/laboreal/1032

DOI: $10.4000 /$ laboreal. 1032

ISSN: 1646-5237

\section{Editora}

Universidade do Porto

\section{Refêrencia eletrónica}

Cirlene de Souza Christo, Jussara Brito, Letícia Pessoa Masson, Marcelo Figueiredo e Paulo César Zambroni-de-Souza, «Trabalho e cooperação: apresentação do dossiê », Laboreal [Online], Volume 15 No1 | 2019, posto online no dia 01 julho 2019, consultado o 25 setembro 2020. URL : http:// journals.openedition.org/laboreal/1032 ; DOI : https://doi.org/10.4000/laboreal.1032

\section{Este documento foi criado de forma automática no dia 25 setembro 2020.}

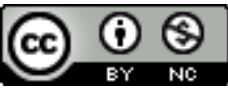

Laboreal está licenciado com uma Licença Creative Commons - Atribuição-NãoComercial 4.0 Internacional. 


\title{
Trabalho e cooperação: apresentação do dossiê
}

\author{
Trabajo y cooperación: presentación del dossier \\ Travail et coopération: présentation du dossier \\ Work and cooperation: presentation of the dossier \\ Cirlene de Souza Christo, Jussara Brito, Letícia Pessoa Masson, Marcelo \\ Figueiredo e Paulo César Zambroni-de-Souza
}

1 A propensão dos seres humanos para a cooperação tem raízes evolutivas antigas (Maturana; Rezepka, 2000). Se eles são o resultado de um processo histórico e não o produto de um plano pré-estabelecido, cabe destacar a importância da cooperação para sua preservação e evolução ao longo desse processo. Um percurso em que o trabalho, como um elemento constitutivo de nossa espécie, revela-se um fator decisivo, seja em nível filogenético ou ontogenético.

2 Assim como os outros mamíferos, desde o início da sua vida, os humanos não conseguem sobreviver sem o amparo de outrem, como bem mostrou Winnicott (2006). o trabalho, por sua vez, permite reviver, de forma transformada, o que se viveu nos teatros da infância (Dejours, 1996), de tal modo que é necessário a presença de outrem, não somente fisicamente, mas de alguém com quem se possa efetivamente cooperar. Apenas assim será possível a cada um desenvolver suas potencialidades, gerando uma zona de desenvolvimento (Vygotski, 1997; Clot, 2006) que a todos favorece. Ao contrário, a realização da atividade com ênfase na competição certamente traz um potencial de nocividade para quem a desempenha, reforçando o individualismo negativo (Castel, 1995) e gerando resultados deletérios para os sujeitos e para a sociedade.

\section{Cooperação, trabalho e saúde}

3 Com o intuito de obter a maximização dos lucros no setor privado e uma suposta melhoria de desempenho na esfera pública - neste caso, sobretudo a partir da lógica da 
new public management (Hood, 1995) -, a organização do trabalho baseada no estímulo à competição tem implementado algumas iniciativas de modo recorrente: a avaliação individual de desempenho, a busca por metas cada vez mais elevadas e a responsabilização do trabalhador sem as condições adequadas para a realização de seu trabalho, entre outras medidas que compelem homens e mulheres a trabalhar sob exigências cada vez maiores.

4 Em uma conjuntura na qual se disseminam de modo acentuado, tanto relações contratuais, quanto formas de gerenciamento do trabalho flexíveis, e não raro precárias, constata-se o agravamento de um quadro potencialmente nocivo à saúde dos trabalhadores. Com a consolidação progressiva no imaginário social de valores baseados no individualismo e na competição, delineia-se um cenário cujo teor dominante aponta para uma divisão crescente das categorias de representação e organização coletiva dos trabalhadores, assim como para a dissolução de laços sociais e a fragmentação dos coletivos de trabalho. Além disso, o recrudescimento de tais práticas, distantes de uma perspectiva de gerenciamento que contemple a gestão coletiva das atividades, pode trazer implicações nefastas para o trabalho, posto que tendem a comprometer aquilo que a cooperação e os coletivos teriam de crucial (ou de positivamente diferencial) para a eficácia dos processos produtivos.

5 Como defendem diversos autores (Yves Schwartz, Yves Clot, Christophe Dejours, Alain Wisner, entre outros), há elementos na atividade de trabalho - dentre os quais a cooperação ocupa lugar central - que são indispensáveis para que se atinja qualidade e produtividade, sem negligenciar a saúde e a segurança. Um compromisso assaz desafiador e que não pode perder de vista os contingentes populacionais diversos que vivem em localidades que circundam as organizações e suas instalações (Oddone; Marri; Gloria; Briante; Chiattella; \& Re, 1986). Neste sentido, cabe lembrar as duas tragédias ocorridas nos anos de 2015 e 2019, no estado brasileiro de Minas Gerais, associadas ao rompimento de barragens utilizadas no setor de mineração, e que resultaram na morte de mais de 300 pessoas, entre trabalhadores e moradores, além de ocasionarem consequências ambientais catastróficas. Não obstante tais eventos não encontrarem precedência no território brasileiro e terem adquirido enorme repercussão internacional, até o momento não se verificou a responsabilização devida dos principais envolvidos, em especial as empresas.

6 Defende-se, neste dossiê temático, que a cooperação contribui para a produção de reservas de alternativas (Schwartz, 2001; Schwartz, Fyad, \& Rufino, 2008) que podem oferecer espaço para elaborar e dar visibilidade a formas de organização do trabalho que não sejam deletérias e possibilitem o desenvolvimento de sociedades mais justas (Schwartz, 2001; Schwartz, Fyad, \& Rufino, 2008; Dejours, 2015). Nessa direção, destacase a importância de se construir ferramentas teórico-práticas que possam amparar projetos de desenvolvimento que não tenham como parâmetro valores meramente mercantis, mas sim que recoloquem a atividade humana em seu centro (Schwartz, 2018) e, dessa forma, estejam a serviço da vida, da saúde, do meio ambiente e da conquista de sentido no trabalho.

7 Foi com o intuito de contribuir para a discussão sobre a cooperação no trabalho, e o que advém quando ela está ausente ou é comprometida, que se convocou a comunidade acadêmica a compor este dossiê. Como ela pode contribuir para a eficácia e a confiabilidade dos sistemas complexos? De que modo seu fortalecimento, assim como a solidariedade nos coletivos de trabalho se relaciona com os conteúdos do trabalho, a 
saúde e a segurança dos(as) trabalhadores(as)? Que implicações para ela advêm das práticas gerenciais baseadas na concorrência e prioritariamente orientadas por resultados e metas, frequentemente valendo-se dos sistemas individualizados de avaliação do desempenho? De que forma ela comparece e/ou precisa ser construída em espaços informais de trabalho? De que modo ela se manifesta ou é deliberadamente negligenciada horizontal ou verticalmente, em espaços tomados ou não pela terceirização? Como se operam as relações fortemente intermediadas por ferramentas com diversos níveis de desenvolvimento tecnológico?

\section{0 que as pesquisas indicam}

Os textos aqui presentes resultam de reflexões surgidas a partir de pesquisas empíricas em diversos meios de trabalho, em diferentes setores produtivos e de formas distintas de organização do trabalho, como elencamos a seguir.

$\mathrm{O}$ artigo de Vanessa Barros e Fabiana Oliveira abre bem a discussão, contribuindo para dar visibilidade ao trabalho de catadores de materiais recicláveis, cuja importância do ponto de vista social e ambiental no quadro brasileiro deve ser destacada. 0 estudo toma como lócus duas cooperativas geridas pela lógica da Economia Solidária. Nesse contexto, as autoras indicam que a cooperação e a solidariedade são construções engendradas no cotidiano das relações de trabalho, que se dão em meio a inúmeras contradições e conflitos. Utilizando abordagem calcada na etnografia e na pesquisaação, o estudo apresentado analisa especificamente o trabalho de catadoras que atuam na triagem do material que chega à sede do empreendimento, considerada o coração dos processos de reciclagem. Segundo as autoras, embora as expressões "cooperativa" e "solidária" estejam no princípio do funcionamento desses empreendimentos, a cooperação não é um elemento dado a priori. Nesse sentido, identificam a produção de arranjos pelas cooperadas que buscam atender, ao mesmo tempo, as necessidades do coletivo e as especificidades de cada trabalhadora. Tais arranjos se configurariam a partir da experiência prática e se baseariam em valores não mercantis, como, por exemplo, a consideração das condições de cada um na gestão da produção.

Em seguida, apresentamos dois artigos que tratam da atividade na mineração: um de autoria de Fernanda Araújo, Vicente Nepomuceno e Denise Alvarez, outro escrito por João César Fonseca, José Newton de Araújo, Carlos Eduardo Vieira e Rodrigo Monteiro. O primeiro deles relata parte de uma experiência de pesquisa-ação em uma mineradora de carvão, localizada no Sul do Brasil, que vem sendo gerida pelos próprios trabalhadores, também organizados na forma de cooperativa. A (des)estruturação dos coletivos de trabalho é tomada pelos autores como via de análise das variações dos índices de produtividade da empresa. Por meio de investigação pautada pela Análise Ergonômica do Trabalho (AET), foram identificados fatores organizacionais que interpelam a atividade de operadores de trator que compõem as equipes de produção nas frentes de exploração subterrânea do carvão. A pressão por produção imediata e a falta de reconhecimento do esforço, acentuadas pela dificuldade de manter fixas as equipes de produção, exerceriam forte influência na priorização (por parte dos operadores) do alcance de metas individuais. No entanto, constata-se que isto se dá em detrimento da totalidade e continuidade do ciclo de operações que compõem o processo produtivo, indicando dificuldades na cooperação, apesar da prescrição desta constar do modelo de gestão adotado. 
11 No segundo estudo, que se passa nas instalações de uma grande empresa de exploração de minério de ferro com atuação na região Norte do Brasil, discute-se a atividade de mineradores que atuam em dupla para operar uma escavadeira elétrica a cabo. Tomando por base a Clínica da Atividade, os autores argumentam que, para além do conhecimento técnico na realização desta atividade, e em contraposição à visão individualizante da empresa, a dimensão coletiva da atividade, instância propiciadora da cooperação no trabalho, é um elemento estrutural do processo produtivo. Esse elemento seria intrínseco ao desenvolvimento do operador, envolvendo tanto o trabalho em duplas, quanto o fazer solidário com os demais membros das equipes de produção na extração mineral estudada.

Na sequência, figuram dois artigos que também evidenciam a cooperação como um componente essencial do desenvolvimento das atividades de trabalho. Ambos remetem à qualidade da prestação de serviços públicos.

Realizando uma investigação junto a magistrados, Ruri Giannini, Laerte Sznelwar, Seiji Uchida e Selma Lancman apresentam materiais que demonstram que o trabalho dos magistrados da Justiça do Trabalho do município de São Paulo, Brasil, conquanto possua um caráter aparentemente solipsista, requer o estabelecimento de redes entre eles. Tais redes, mesmo que informais, revelam-se necessárias para enfrentar aquilo que ultrapassa o que é exigido no concurso para tal função e o que é oferecido no treinamento da Escola de Magistratura. Munidos do olhar da Ergonomia da Atividade e da Psicodinâmica do Trabalho, sinalizam que, além das formas de avaliação de juízes serem basicamente quantitativas e individuais, não há mecanismos institucionais que potencializem as trocas entre pares e valorizem o retorno da experiência, o que, segundo os autores, pode comprometer a qualidade e a produtividade dos serviços.

As análises empreendidas por Yana Felix, Anísio Araújo e Thaís Máximo vão nesta mesma direção, ao mostrarem que a cooperação é determinante para a qualidade da assistência prestada pelas equipes do Serviço de Atendimento Móvel de Urgência (SAMU) em um estado da região Nordeste do Brasil. Lançando mão dos aportes da Psicodinâmica do Trabalho e da Sociologia (em especial Bruno Maggi e Philippe Zarifian), referem-se à demanda intrínseca por cooperação, no desenvolvimento das atividades, que não se restringe à estabelecida pelos diferentes trabalhadores da saúde - condutores, médicos e enfermeiros(as). Com efeito, também enfatizam a necessária cooperação dos usuários (do próprio paciente, assim como dos familiares e, em muitos momentos, de pessoas que estejam próximas ao local de atendimento) para a realização de atendimentos dessa natureza e a eficácia dos serviços prestados. Os autores indicam que a comunicação é um componente essencial da cooperação nesse contexto específico, que se desenvolve com a experiência prática e no viver juntos, seja em espaços formais ou informais. A leitura do artigo nos remete a uma reflexão sobre as graves implicações de eventuais obstáculos ao estabelecimento de cooperação entre os protagonistas das atividades desenvolvidas no atendimento de casos de urgência e emergência, tanto no que tange a seu êxito, quanto no que diz respeito à saúde dos trabalhadores envolvidos.

Por fim, dois artigos demonstram o papel fundamental da cooperação na gestão dos riscos e nas ações de saúde e segurança do trabalho. O primeiro, de Marcelle La Guardia e Francisco Lima, aborda a atividade de eletricistas de manutenção de linhas de transmissão de energia. 0 texto debruça-se sobre uma controvérsia ocorrida em uma concessionária estatal do setor (no Sudeste do Brasil) e que dividia opiniões a respeito 
da reorganização (redução) das equipes de eletricistas. A solução passou por uma pesquisa que se valeu da análise ergonômica do trabalho (AET) e colocou o trabalho real no centro do estudo, voltando-se o olhar para a atividade e as relações intersubjetivas, o que possibilitou desvendar como a cooperação e a confiança são construídas no dia a dia, e como atuam como base para a eficiência da gestão coletiva dos riscos em situações complexas.

Em uma perspectiva afim, o texto de Pamela Astudillo e Carlos Ibarra parte da hipótese que a precarização das relações e condições de trabalho no Chile, que acompanha o modelo neoliberal, tem enfraquecido o trabalho coletivo e a cooperação entre o(a)s trabalhadore(a)s. Traz uma discussão sobre a formação em ergonomia instituída no Chile, após a adoção de uma política nacional de saúde e segurança do trabalho (SST), impulsionada pelo acidente dos 33 mineiros na mina de San José em 2010. Diferentemente do que predominou, segundos os autores - uma formação "técnica" calcada na transmissão clássica de conhecimentos por especialistas -, sua pesquisa propôs a formação-ação em ergonomia (da atividade) e gênero, valorizando o conhecimento e a experiência dos trabalhadores.

O estudo contemplou diversos setores produtivos (da indústria do salmão aos transportes, passando pelos serviços de saúde), em que se deram formações curtas de dirigentes sindicais e profissionais de SST. Para o artigo, os autores elegeram casos mais fortemente relacionados a trabalhos em que havia o pagamento de incentivos por produção, indicando sua associação ao elevado número de lesões musculoesqueléticas e ao enfraquecimento das relações de cooperação, devido à falta de coesão e à competição geradas pelo sistema de trabalho. Para os autores, a análise da atividade no contexto de formação permitiu gerar mudanças na representação do problema, a partir, por exemplo, da compreensão de que a cooperação entre colegas pode representar um fator de proteção à SST.

\section{Convite à leitura}

Entendemos que os textos que compõem o dossiê evidenciam a atualidade e a importância do tema da cooperação, indicando desafios relativos à sua melhor compreensão, tanto nas situações em que as atividades possuem um caráter aparentemente solipsista, quanto naquelas em que se pressupõe o trabalho coletivo. Os autores dos artigos também trazem questionamentos sobre situações supostamente favoráveis à cooperação, como em cooperativas, ressaltando que esse aspecto do trabalho nunca está dado a priori, envolvendo a criação de rearranjos para a realização das atividades. Além disso, incorporam como ponto comum o fato de que um olhar cuidadoso e detido sobre a atividade - a partir de métodos diversos de análise do trabalho e formação-ação - pode ser bastante frutífero para a instalação do diálogo sobre o trabalho e para o questionamento das normas e valores muitas vezes impostos pela organização do trabalho e que são deletérias para a construção dos laços de cooperação.

19 Se, por um lado, os artigos trazem elementos que indicam os efeitos negativos dos bloqueios à cooperação no trabalho para a eficiência e eficácia dos processos produtivos, para a gestão dos riscos e para a saúde dos trabalhadores envolvidos; por outro, revelam formas de cooperação tecidas no desenvolvimento das atividades, que se 
constroem e se consolidam com o tempo, com a experiência e o fortalecimento dos vínculos.

Por fim, esperando que esse dossiê contribua para uma melhor compreensão do trabalho em suas configurações na contemporaneidade, convidamos você, leitor, a usufruir de sua leitura, salientando que: se o individualismo e a competição se colocam como tendências hegemônicas, novos caminhos podem ser construídos, pois, "no que diz respeito aos sujeitos humanos, ninguém conhece nem conhecerá integralmente as condições iniciais de seu objeto de estudo, como também ninguém conhece as suas próprias condições. É por isso que a história sempre nos reserva surpresas" (Schwartz, 1992, p. 64).

\section{BIBLIOGRAFIA}

Castel, R. (1995). Les métamorphoses de la question sociale: une chronique du salariat. Paris: Fayard.

Clot, Y. (2006). La fonction psychologique du travail. Paris: PUF.

Dejours, C. (2015). Le choix, Souffrir au travail n'est pas une fatalité. Montrouge: Bayard.

Dejours, Y. (1996). Uma nova visão do sofrimento nas organizações. In J.-F. Chanlat (Org.). O indivíduo na organização: dimensões esquecidas (pp. 150-173). São Paulo: Atlas.

Hood, C. (1995). The "new public management" in the 1980s: Variations on a theme. Accounting, Organizations and Society. 20(2-3), 93-109. https://doi.org/10.1016/0361-3682(93)E0001-W

Maturana, H.; Rezepka, Sima (2000). Formação humana e capacitação. Petrópolis: Vozes.

Oddone, I., Marri, G., Gloria, S., Briante, G., Chiattella, M., \& Re, A. (1986). Ambiente de trabalho: a luta dos trabalhadores pela saúde. São Paulo: Hucitec.

Schwartz, Y. (2018). Prefácio. In R. Di Ruzza, M. Lacomblez, \& M. Santos (Orgs). Ergologia, Trabalho, Desenvolvimentos (pp. 16-24). Belo Horizonte: Fabrefactum.

Schwartz, Y. (2001). Introduction aux IIIèmes Rencontres. In Association pour la Promotion des Recherches Interdisciplinaires sur le Travail - APRIT (Eds) Actes des IIIèmes Rencontres: Travail et civilisation: penser l'ouverture des espaces, des métiers, des pratiques (pp. 21-28). Université de Provence: Marseille.

Schwartz, Y. (1992). Travail et usage de soi. In Y. Schwartz (Org.). Travail et philosophie convocations mutuelles (pp. 43-66). Toulouse: Octarès.

Schwartz, Y. \& Adriano, R., Abderrahmane, F. (cols.) (2008). Revisitar a actividade humana para colocar as questões do desenvolvimento: projecto de uma sinergia franco-lusófona. Laboreal, 4(1), 10-22. http://laboreal.up.pt/revista/artigo.php?id=48u56oTV658223439657; 8:3872

Vygotski, L. S. (1997). Pensée et Langage. Paris: La Dispute.

Winnicott, D. (2006). The family and individual development. London: Routledge. 


\section{AUTORES}

\section{CIRLENE DE SOUZA CHRISTO}

Instituto de Psicologia da Universidade Federal do Rio de Janeiro. Av. Pasteur, 250 - Urca, Rio de Janeiro, RJ, CEP: 22290-902, Brasil; cirlenechr@gmail.com

\section{JUSSARA BRITO}

Fundação Oswaldo Cruz; Rua Leopoldo Bulhões 1480, Manguinhos, Rio de Janeiro, RJ, CEP: 21041-210, Brasil; jussara@ensp.fiocruz.br

\section{LETÍCIA PESSOA MASSON}

Centro de Estudos da Saúde do Trabalhador e Ecologia Humana, Escola Nacional de Saúde Pública Sérgio Arouca, Fiocruz; Rua Leopoldo Bulhões 1480, Manguinhos, Rio de Janeiro, RJ, CEP: 21041-210, Brasil; leticiamasson@ensp.fiocruz.br

\section{MARCELO FIGUEIREDO}

Escola de Engenharia - Departamento de Engenharia de Produção, Universidade Federal Fluminense Av. Passo da Pátria 156, São Domingos, Niterói, RJ, CEP: 22210-240, Brasil; marceloparada@uol.com.br

\section{PAULO CÉSAR ZAMBRONI-DE-SOUZA}

Programa de Pós-graduação em Psicologia Social - Departamento de Psicologia, Universidade Federal da Paraíba; Cidade Universitária, s/nº , Bairro Castelo Branco, João Pessoa, PB, CEP: 58051-900, Brasil; paulozamsouza@yahoo.com.br 